\section{UCDNN}

LIBRARY
University of Connecticut OpenCommons@UConn

UCHC Articles - Research

University of Connecticut Health Center Research

$2-2012$

\title{
Under-treatment of Depression in Older Persons
}

Lisa C. Barry

University of Connecticut School of Medicine and Dentistry

Follow this and additional works at: https://opencommons.uconn.edu/uchcres_articles Part of the Medicine and Health Sciences Commons

\section{Recommended Citation}

Barry, Lisa C., "Under-treatment of Depression in Older Persons" (2012). UCHC Articles - Research. 166.

https://opencommons.uconn.edu/uchcres_articles/166 


\title{
Under-treatment of Depression in Older Persons
}

\author{
Lisa C. Barry, Ph.D., M.P.H. ${ }^{1}$, Janet J. Abou, M.D. ${ }^{2}$, Arthur A. Simen, M.D., Ph.D ${ }^{3}$, and \\ Thomas M. Gill, M.D. 4 \\ ${ }^{1}$ UConn Center on Aging, University of Connecticut Health Center, Farmington, Connecticut \\ ${ }^{2}$ University of California Los Angeles Medical Center, Los Angeles, California \\ ${ }^{3}$ Department of Psychiatry, Yale University School of Medicine, New Haven, Connecticut \\ ${ }^{4}$ Department of Internal Medicine, Yale University School of Medicine, New Haven, Connecticut
}

\begin{abstract}
Background-Due to the cross-sectional design of most existing studies, longitudinal characterization of treatment for depression in older persons is largely unknown.
\end{abstract}

Method-754 men and women (aged 70+ years) underwent monthly assessments of mental health professional use and 18-month assessments of antidepressant medication use and depressive symptoms over 9 years. Scores of $\geq 20$ on the Center for Epidemiological Studies-Depression (CES-D) scale denoted depression. We evaluated trends in depression treatment over time in the entire sample and among the depressed participants. Using generalized linear models, we determined characteristics associated with receiving treatment for depression in these groups and among those with persistent depression.

Results-During the 9-year follow-up period (1998-2007), 339 (45.0\%) of the participants reported depression treatment. Over time, antidepressant use alone decreased ( $p$ trend $<0.001$ ) while treatment with both antidepressants and a mental health professional increased ( $\mathrm{p}$ trend $=$ 0.002 ). Of the $286(27.9 \%)$ depressed participants, between $43 \%$ and $69 \%$ did not receive depression treatment during any 18 -month interval. $30.5 \%$ of the 121 participants with persistent depression did not receive treatment during the study period. Increasing number of years of education, decreasing cognitive status score, and being physically frail were associated with a higher likelihood of receiving treatment in all models.

Limitations-Pre-baseline depression, pre-baseline treatment, and indication for treatment were unavailable.

Conclusions-Our findings indicate that the profile of treatment for depression in older persons has changed over time, that depressed older persons, including those with persistent depression, are under-treated, and that patient characteristics influence receipt of treatment.

\section{Keywords}

depression; treatment; elderly; longitudinal

\footnotetext{
C 2011 Elsevier B.V. All rights reserved.

Address correspondence to: Lisa C. Barry, Ph.D., M.P.H.; UConn Center on Aging, University of Connecticut Health Center, Farmington, Connecticut 06030-5215, Telephone: (860) 679-6264, Fax: (860) 679-7960; LiBarry @uchc.edu.

Publisher's Disclaimer: This is a PDF file of an unedited manuscript that has been accepted for publication. As a service to our customers we are providing this early version of the manuscript. The manuscript will undergo copyediting, typesetting, and review of the resulting proof before it is published in its final citable form. Please note that during the production process errors may be discovered which could affect the content, and all legal disclaimers that apply to the journal pertain.
} 


\section{Background}

Whereas major depression affects only about $1 \%$ to $2 \%$ of community-dwelling persons aged 65 years or older (Blazer, 2003), clinically significant depressive symptoms are more common. Often referred to as "depressed mood" or simply "depression," clinically significant depressive symptoms affect between $8 \%$ to $20 \%$ of this population (Blazer, 2003). Both major depression and depressive symptoms are associated with increased healthcare costs (Katon et al., 2003) and adverse outcomes, including exacerbation of coexisting medical illness, disability in activities of daily living, and mortality (Carnethon et al., 2007; Penninx et al., 1999; Unutzer et al., 2002). Because many antidepressant medications are safe and well-tolerated in older persons (Mamdani et al., 2000; Sonnenberg et al., 2008), they are considered a first-line treatment for a spectrum of depressive disorders in this population, including clinically significant depressive symptoms (Alexopoulos et al., 2001). Receiving therapy from a mental health professional, such as a psychiatrist, psychologist, or counselor, also has been found to be effective in treating depression in this population (Cuijpers et al., 2006; Pinquart et al., 2006). A growing body of evidence, however, indicates widespread under-treatment of depressive disorders in older persons. This finding seems to be consistent across populations, including those who are communitydwelling (Garrido et al., 2011; Sonnenberg et al., 2008; Unutzer et al., 2003; Wilson et al., 1999), hospitalized (Koenig and George, 1998), or residing in a nursing home (Streim et al., 2000). Yet, with few exceptions (Unutzer et al., 2003), prior studies evaluating treatment of depression in older persons largely have evaluated either the use of antidepressant medications or psychotherapy, but not both. Furthermore, due to the cross-sectional design of most prior studies (Garrido et al., 2011; Mamdani et al., 2000; Sonnenberg et al., 2003; Unutzer et al., 2003), the extent of potential under-treatment of older persons with depression, including persistent depression, is largely unknown.

We sought to describe the profile of depression treatment (i.e., antidepressant medication use and use of a mental health professional) over time in a large cohort of older persons. In addition, to better understand the scope of potential under-treatment of depression in older persons, we set out to characterize treatment in depressed, older persons over time and to identify factors associated with potential under-treatment. To accomplish these aims, we used data from a unique longitudinal study that includes up to six assessments of depressive symptoms and antidepressant use at 18-month intervals and monthly assessments of mental health professional use for 9 years.

\section{Methods}

\section{Study Population}

Participants were members of the Precipitating Events Project (PEP), a longitudinal study of 754 initially non-disabled, community-living persons aged 70 years or older (Gill et al., 2001). Participants were identified from 3,157 age-eligible members of a health plan in New Haven, Connecticut. The primary inclusion criteria were English speaking and requiring no personal assistance with bathing, dressing, transferring from a chair, and walking across a room. The participation rate was 75.2\% (Gill et al., 2001). The Human Investigation Committee at Yale University approved the study.

\section{Data collection}

Beginning on March 23, 1998, comprehensive face-to-face assessments were completed at baseline and subsequently at 18-month intervals for 90 months, while telephone interviews were completed monthly for up to 108 months. Deaths were ascertained from the local obituaries and/or from an informant during a subsequent telephone interview. Four hundred 
and five (53.7\%) participants died (median follow-up of 68 months) and 35 (4.6\%) dropped out of the study (median follow-up of 24 months). Consequently, there were 754, 681, 628, 559, 495, and 439 participants available at the baseline, 18-month, 36-month, 54-months, 72-month, and 90-month assessments, respectively.

During the baseline assessment, data were collected on demographic factors, including age, sex, race, and years of education. During each of the comprehensive assessments, data were collected on three important clinical factors. Medical comorbidity was ascertained based on a count of up to nine self-reported, physician-diagnosed chronic conditions: hypertension, myocardial infarction, congestive heart failure, stroke, diabetes mellitus, arthritis, hip fracture, chronic lung disease, and cancer. Cognitive status was assessed by the Folstein Mini-Mental State Examination (MMSE), where MMSE scores range from 0 to 30, with higher scores representing better cognitive status (Folstein et al., 1975). Physical frailty was assessed using a rapid gait test in which participants were instructed to walk a 10-foot (3.048-m) course "as fast as it feels safe and comfortable," turn around, and walk back. Participants who completed the task in $>10$ seconds were considered to be physically frail (Gill et al., 1995).

Depressive symptoms-Depressive symptoms were assessed using the 11-item Center for Epidemiological Studies-Depression scale (CES-D) (Beekman et al., 1997; Kohout et al., 1993). Scores were transformed to be compatible with the 20-item CES-D (Kohout et al., 1993). Total scores range from 0 to 60 , with higher scores indicating more depressive symptoms. Participants scoring $\geq 20$ were considered as having "clinically significant depressive symptoms" or "depressed." A CES-D score of 20 or higher has previously been shown to enhance the likelihood of detecting major depression among community-living older persons (Beekman et al., 2002). Data on depressive symptoms were complete for $100 \%$ of the participants at baseline and $95 \%, 93 \%, 91 \%, 90 \%$, and $89 \%$ of the nondecedents at 18, 36, 54, 72, and 90 months, respectively. Furthermore, "persistent depression" was defined as having a CES-D score $\geq 20$ during 2 consecutive face-to-face assessments.

Depression Treatment-During the face-to-face assessments, participants were asked to retrieve all of their medications. If a medication was not retrieved, the nurse asked to see the participant's medication list. If a list was unavailable, participants were asked to recall medications that they had taken during the prior two weeks. All medications, but not the doses or dosing schedule, were recorded. Participants were coded as having taken an antidepressant medication based on a code of 28.16.04 from the American Hospital Formulary System (AHFS). Because trazodone and amitriptyline were commonly used during the study period for other indications, including sleep and pain (Mayers et al., 2005; Saarto and Wiffen, 2007), antidepressant medication use was assessed with and without these medications included. In addition, during the monthly assessments, participants were asked "Since we last talked, have you seen a psychiatrist, psychologist, or counselor?" Because the indication for use of a mental health professional was not ascertained, we used a conservative approach to assessing this type of treatment for depression. If a participant responded "yes" to the aforementioned question during any of the monthly assessments in a given 18-month interval (e.g., between the 18-month and 36-month assessments), s/he was coded as having seen a mental health professional for depression during that interval. This rather inclusive definition enabled us to report the potential maximum percentage of participants being treated for depression. Participants were subsequently assigned to one of four treatment categories during each interval: having taken an antidepressant medication only, having seen a mental health professional only, having both taken an antidepressant medication and seen a mental health professional, and having received neither treatment. 


\section{Statistical analysis}

During each of the 6 intervals, we determined the percentage of all participants who received depression treatment. Using Cochran-Armitage tests for trend, we then evaluated trends over time in the percentage of participants receiving antidepressants only, seeing a mental health professional only, or using both treatments. We then ran generalized linear models using a generalized estimating equation approach, where CES-D score, medical comorbidity, cognitive status, and physical frailty were entered as time-varying covariates, to determine the characteristics associated with receiving treatment for depression. We repeated this procedure among those who were depressed (i.e., CES-D score $\geq 20$ ) at the start of an 18-month interval, but excluded CES-D score from the statistical model. In addition, we determined the percentage of participants who were depressed during at least 2 consecutive intervals (i.e., persistent depression), yet never reported receiving treatment for depression and used the same modeling approach as was indicated for all depressed participants. All statistical tests were 2-tailed, and $P<0.05$ was considered statistically significant. Analyses were performed used using SAS statistical software, version 9.2.

\section{Results}

\section{Description of the Sample}

Table 1 presents the baseline characteristics of the sample. The mean age was $78.4 \pm 5.3$ years; two-thirds of the participants were women, $90.4 \%$ were white, and $25.7 \%$ were physically frail. On average, participants had $1.8 \pm 1.2$ chronic conditions and an MMSE score of $26.8 \pm 2.5$. There were $100(13.3 \%)$ participants who were depressed (i.e., CES-D $\geq 20$ ).

\section{Depression Treatment Over Time in the Entire Sample}

During the 108-month study period, 339 (45.0\%) participants reported receiving depression treatment. After the exclusion of trazodone or amitriptyline, this number decreased to 319 (42.3\%) participants. Overall, the percentage of participants receiving any depression treatment, including trazodone or amitriptyline, increased over time ( $\mathrm{p}$ trend $<0.001$ ), with $112(14.9 \%), 120$ (17.6\%), 140 (22.3\%), $146(26.2 \%), 142(28.7 \%)$, and $160(36.4 \%)$ of the sample receiving treatment during the six 18-month intervals from baseline to 108 months. Figure 1 presents the profile of depression treatment, among the participants receiving treatment, during each interval throughout the study. Whereas antidepressant use alone was the most common depression treatment reported, the percentage of participants who reported taking antidepressant medications only decreased over time ( $p$ trend <0.001). In contrast, there was an increase over time in the percentage of participants receiving both treatments (i.e., antidepressant medications and seeing a mental health professional) $(\mathrm{p}=0.002)$. The percentage of participants seeing a mental health professional only increased over time, but the trend was non-significant.

Among the participants reporting antidepressant use, Selective Serotonin Reuptake Inhibitors (SSRIs), including citalopram, escitalopram, fluoxetine, paroxetine, and sertraline, were the most common antidepressant medications reported during each time interval (range $45.0 \%$ to $65.9 \%$ ), followed by tricyclic antidepressants (TCAs), including amitriptyline, desipramine, doxepin, imipramine, and nortriptyline (range $13.1 \%$ to $43.8 \%$ ), and non-SSRI/ non-tricyclic antidepressants, including bupropion, duloxetine, mirtazapine, serzone, trazodone, and venlafaxine (range $18.8 \%$ to $35.2 \%$ ). The percentage of participants using SSRIs increased during each subsequent time interval, while the percentage of participants using TCAs decreased. As shown in Table 2 (first results column), several characteristics were associated with depression treatment among all participants. With every 1-point increase in age and MMSE score, the likelihood of being treated decreased by $3 \%$ and $11 \%$, 
respectively. In contrast, with every 1-point increase in years of education and CES-D score, the likelihood of being treated increased by $6 \%$ and $3 \%$ respectively. Female sex and being physically frail each were independently associated with a greater likelihood of being treated. Findings remained consistent when the model was re-run without including trazodone or amitriptyline as antidepressant medications, with the exception of sex $(\mathrm{OR}=1.32,95 \%$ CI $0.97,1.79)$ and education $(\mathrm{OR}=1.05,95 \%$ CI $0.99,1.11)$, which were no longer significantly associated with treatment.

\section{Depression Treatment in the Depressed Participants}

A total of 286 (27.9\%) participants reported clinically significant depressive symptoms (i.e., depressed) at some point during the study period, with 100 (13.3\%), $116(17.2 \%), 124$ (20.3\%), 109 (20.2\%), 91 (19.3), and 96 (23.2\%) participants depressed at baseline, 18, 36, 54,72 , and 90 months, respectively. Of these 286 participants, 158 (55.2\%) were depressed at more than one time point and $142(49.7 \%)$ never reported receiving treatment. As shown in Figure 2, between $43 \%$ and $69 \%$ of the depressed participants did not receive any depression treatment during a specific time interval. These percentages increased after the exclusion of participants who reported trazodone or amitriptyline as their only treatment, with values ranging between $48 \%$ and $75 \%$. The profile of depression treatment changed during the follow-up period, with significant increases over time in the percentages of participants seeing a mental health professional only $(\mathrm{p}$ trend $=0.01)$ or receiving both treatments ( $\mathrm{p}$ trend $<0.001$ ). As shown in Table 2 (second results column), the same characteristics associated with depression treatment among all participants were also associated with treatment among the depressed participants, with the exception of sex. In addition, with the exception of MMSE score, the effect sizes for each of these characteristics were greater among the depressed participants. The results did not change after the model was re-run without including trazodone or amitriptyline as antidepressant medications.

Of the 121 participants who were depressed for at least 2 consecutive intervals, indicating persistent depression, $37(30.5 \%)$ reported receiving no depression treatment. This number increased to $40(33.1 \%)$ after the exclusion of trazodone and amitriptyline. Among participants with persistent depression, the likelihood of receiving depression treatment, as shown in Table 2 (third results column), increased by approximately $32 \%$ as the number of chronic conditions increased and decreased by $9 \%$ with every 1-point increase in MMSE score. Increasing years of education and being physically frail were associated with an increased likelihood of receiving treatment. However, these latter two characteristics were no longer significantly associated with treatment after the model was re-run without including trazodone or amitriptyline as antidepressant medications.

\section{Discussion}

In this longitudinal study of older persons, which included multiple assessments of depressive symptoms and treatment for depression over 9 years, we found that the profile of depression treatment changed over time, with trends indicating an increase in the use of both antidepressant medications and a mental health professional. Our findings confirmed potential under-treatment of depressed older persons. In addition, we also found that many older persons with persistent depression are not being treated and that patient characteristics, particularly clinical factors, influence receipt of treatment.

Antidepressant medications have long been the most commonly used treatment for depression in older persons (Mottram et al., 2006). Although seeing a mental health professional is also considered to be an effective treatment for depression in this population (Williams et al., 2000), prior longitudinal studies, with one exception (Unutzer et al., 2003), have not evaluated use of this treatment modality over time (Mamdani et al., 2000; 
Sonnenberg et al., 2003; Sonnenberg et al., 2008; Wilson et al., 1999). A more inclusive definition of treatment, such as is used in the present study, likely provides a more complete picture of the scope of depression treatment among older persons. While the percentage of participants receiving treatment for depression increased over time, the overall increase was largely attributable to the rise in the percentage of older persons receiving treatment from a mental health professional. In fact, we found that the percentage of older persons reporting antidepressant medication use only steadily decreased over time. These results suggest that there may be an ongoing shift in how clinicians are treating depression in older persons. This shift may reflect a diminishing fear of the stigmatization of receiving treatment for depression that has been previously reported in older persons (Givens et al., 2006; Montano, 1999; Sirey et al., 2001) and perhaps a greater acceptance, by both patients and physicians, of nonpharmacologic therapy as an effective treatment.

We found that the majority of participants with clinically significant depressive symptoms in any 18-month interval were not taking an antidepressant medication or receiving treatment from a mental health professional. This finding is consistent with those of prior studies that have demonstrated widespread under-treatment of depression in older persons (Garrido et al., 2011; Sonnenberg et al., 2003; Unutzer et al., 2003; Wilson et al., 1999). While it is possible that some of the participants, particularly those who were depressed during only one time interval across the 108-month study period, were being managed appropriately, strong evidence suggests that under-treatment is often attributable to misrecognition and under-diagnosis of depression resulting from a combination of physician, patient, and system-level factors (Mitchell et al., 2010; Park and Unutzer, 2011). Despite the growth of dedicated geriatric centers in academic medical institutions across the U.S.(Warshaw et al., 2006), most older persons in this country receive treatment for depression from primary care physicians in more traditional practices (Crystal et al., 2003; Harman et al., 2006) who often lack specialty training in geriatric assessment and care (Nutting et al., 2000). Without expertise in geriatric medicine, physicians may be more likely to misdiagnose depression as dementia (Wright and Persad, 2007), may mistakenly attribute depressive symptoms as an acceptable response to aging-related illnesses or conditions (Kennedy and Marcus, 2005), or may interpret depressive symptoms as an inevitable response to loss of social support and socialization (Oxman and Hull, 2001). Other factors contributing to the under-diagnosis of depression in this population include limited time for physicians to discuss mental health during office visits (Tai-Seale et al., 2007) and older patients' general reluctance to report psychological symptoms (Lebowitz et al., 1997; Lyness et al., 1995). Finally, older persons may be discouraged from seeking mental health-related care by financial considerations. During our study period, Medicare recipients were required to pay $50 \%$ for mental health services as compared with $20 \%$ for physical health conditions. This policy, discriminating against outpatient mental health services, has recently been rescinded by recent legislation under the Medicare Improvements for Patients and Providers Act [H.R. 6331; $110^{\text {th }}$ Congress; July 15, 2008], but is being phased out gradually, with copayments dropping to $20 \%$ by 2014 . Whether the new policy leads to improved diagnosis and treatment of depression in older persons should be the focus of future research.

Unlike most prior studies describing depression treatment in older persons (Garrido et al., 2011; Mamdani et al., 2000; Sonnenberg et al., 2003; Unutzer et al., 2003), the present study included repeated evaluations of depressive symptoms and treatment. These repeated assessments enabled us to determine that nearly one third of participants with persistent depression did not receive treatment. Because we used a conservative approach to define depression treatment (as described in the Methods), we consequently report the best-case scenario regarding treatment for depression. Consequently, our findings indicate that there is still potential opportunity for improved treatment among older persons with persistent depression. Future studies that evaluate depression treatment, including antidepressant use 
and seeing a mental health professional, among older persons with persistent depression are needed to corroborate our findings.

Not surprisingly, among all study participants, we found that the likelihood of receiving treatment for depression increased with increasing CES-D score. Our findings also indicated that several demographic factors were associated with treatment. Age was inversely associated with receiving treatment among all participants and among all depressed participants, but not among those with persistent depression. This inverse association, which has been reported previously (Sonnenberg et al., 2000; Wang et al., 2005), may be due to under-recognition of depression as well as factors such as an inability to pay for treatment among the oldest old or physicians' concerns regarding antidepressant use and risk of adverse pharmacologic interactions (Caughey et al., 2010; Hajjar, 2007). Among those with persistent depression, however, clinicians' concerns regarding treating increasingly older patients may be outweighed by their concerns regarding the potentially negative effects of persistent depression on patients' health. Education was associated with treatment across all participants and among the depressed groups, with the likelihood of receiving treatment increasing with increasing number of years of education. In older persons, a greater number of years of education has previously been associated with an increased likelihood of taking antidepressants (Blazer et al., 2005; Sambamoorthi et al., 2003) and seeking treatment for depression (Nyunt et al., 2009). Once we excluded trazodone and amitriptyline as antidepressant medications, however, education was no longer associated with treatment in all participants and in those with persistent depression. More research is needed to understand if the association between education and treatment is driven by factors such as income and perception of unmet healthcare needs. Furthermore, the lack of an association between sex and treatment among all participants (when trazodone and amitriptyline were not included as antidepressant medications), and among depressed participants as well as those with persistent depression, challenges prior research indicating that older women are more likely than older men to receive treatment for depression (Klap et al., 2003; Unutzer et al., 2003). It is possible that this discordance in findings is attributable to our inability to distinguish persons with major depressive disorder (MDD) from those who did not meet criteria for MDD, since prior studies included persons with diagnostically-confirmed depression. To mitigate this concern, we used a cut-point of 20 or higher on the CES-D, which increased the likelihood of detecting major depression. It is more likely that the discordance in findings is attributable to our ability to account for clinical factors, including cognitive status, number of chronic conditions and physical frailty, which were not evaluated in prior studies (Klap et al., 2003; Unutzer et al., 2003).

Cognitive impairment, comorbid medical conditions, and physical frailty are highly prevalent in depressed, older persons (Fischer et al., 2003; Hajjar et al., 2009; Kohler et al., 2010; Panza et al., 2010), and their omission from most prior studies is a significant limitation. We found that worsening cognitive status and being physically frail were consistently associated with a higher likelihood of receiving treatment, and that increasing number of chronic conditions was associated with an increased likelihood of receiving treatment among participants with persistent depression. Yet, with few exceptions (Garrido et al., 2011; Sonnenberg et al., 2008), prior studies have not evaluated the association between these factors and treatment for depression. Older patients with cognitive impairment, medical comorbidities, and physical frailty may display more somatic symptoms of depression than depressed patients without these conditions and, subsequently, may be more readily prescribed depression treatment. Treatment of older persons with these conditions, however, is challenging due to their increased risk of adverse drug reactions (Caughey et al., 2010) and subsequent disability (Fried et al., 2004), which may inhibit patients' ability to regularly seek treatment from a mental health professional. 
While the prospective study design provided a unique opportunity to characterize depression treatment according to depression status over a 9-year period, several potential limitations should be acknowledged. First, information was not available regarding the diagnosis or treatment of depression prior to the baseline assessment. Second, we did not have information regarding the dose, dosing schedule, or adherence for the antidepressant medication use. Consequently, the percentage of depressed participants who were undertreated may actually be higher than what is reported in our study due to inadequate dosing or lack of adherence. Third, information was not available regarding the indication for antidepressant medication use or the reason for seeing a psychiatrist, psychologist, or counselor. The use of a rather inclusive definition of depression treatment provides the best case scenario for the percentage of participants being treated. Finally, because our study participants were members of a single health plan, initially non-disabled, and at least aged 70 years at baseline, the generalizability of our findings to other older adult populations may be questioned. However, the demographic characteristics of our study population, including years of education, closely mirror those of persons 70 years or older in New Haven County, Connecticut, which, in turn, are comparable to those in the United States as a whole, with the exception of race. New Haven County has more non-Hispanic whites in this age group than in the United States (91\% versus 84\%). Furthermore, generalizability depends not only on the characteristics of the study population but also on its stability over time (Szklo, 1998). The high participation rate, completeness of data collection, and low rate of attrition for reasons other than death all enhance the generalizability of our findings and at least partially offset the absence of a population-based sample.

In conclusion, our findings indicate that the profile of treatment for depression in older persons has changed over time, particularly with an increase in the combined use of antidepressant medications and use of a mental health professional. However, despite our broad definition of treatment for depression, we still found evidence of under-treatment among depressed, older persons, including those with persistent depression. Our findings also indicate that clinical factors such as cognitive status, number of chronic conditions, and physical frailty may influence receipt of treatment in older persons more than factors previously thought to be associated with treatment in this population, such as increasing age and female sex. Our work provides a foundation for future longitudinal studies to provide a more detailed profile of depression treatment in older persons, and evaluate factors associated with receipt of treatment, while accounting for depression status and indication for treatment.

\section{Acknowledgments}

We thank Denise Shepard, BSN, MBA, Andrea Benjamin, BSN, Paula Clark, RN, Martha Oravetz, RN, Shirley Hannan, RN, Barbara Foster, Alice Van Wie, BSW, Patricia Fugal, BS, Amy Shelton, MPH, and Alice Kossack for assistance with data collection; Wanda Carr and Geraldine Hawthorne for assistance with data entry and management; Evelyne Gahbauer, MD, MPH and Linda Leo-Summers, MPH who provided data management and programming; Peter Charpentier, MPH for development of the participant tracking system; and Joanne McGloin, MDiv, MBA for leadership and advice as the Project Director.

\section{References}

Medicare Improvements for Patients and Providers Act H.R. 6331, United States.

Alexopoulos GS, Katz IR, Reynolds CF, Carpenter D, Docherty JP, Ross RW. Pharmacotherapy of depression in older patients: a summary of the expert consensus guidelines. Journal of Psychiatric Practice. 2001; 7:361-376. [PubMed: 15990550]

Beekman AT, Deeg DJ, Van Limbeek J, Braam AW, De Vries MZ, Van Tilburg W. Criterion validity of the Center for Epidemiologic Studies Depression scale (CES-D): results from a community-based 
sample of older subjects in The Netherlands. Psychological Medicine. 1997; 27:231-235. [PubMed: 9122304]

Beekman ATF, Geerlings SW, Deeg DJH, Smit JH, Schoevers RS, de Beurs E, Braam AW, Penninx BWJH, van Tilburg W. The natural history of late-life depression: a 6-year prospective study in the community. Archives of General Psychiatry. 2002; 59:605-611. [PubMed: 12090813]

Blazer DG. Depression in late life: review and commentary. Journals of Gerontology Series ABiological Sciences \& Medical Sciences. 2003; 58:249-265.

Blazer DG, Hybels CF, Fillenbaum GG, Pieper CF. Predictors of antidepressant use among older adults: have they changed over time? American Journal of Psychiatry. 2005; 162:705-710. [PubMed: 15800142]

Carnethon MR, Biggs ML, Barzilay JI, Smith NL, Vaccarino V, Bertoni AG, Arnold A, Siscovick D. Longitudinal association between depressive symptoms and incident type 2 diabetes mellitus in older adults: the cardiovascular health study. Archives of Internal Medicine. 2007; 167:802-807. [PubMed: 17452543]

Caughey GE, Roughead EE, Shakib S, McDermott RA, Vitry AI, Gilbert AL. Comorbidity of chronic disease and potential treatment conflicts in older people dispensed antidepressants. Age \& Ageing. 2010; 39:488-494. [PubMed: 20511245]

Crystal S, Sambomoorthi U, Walkup J, Akinsigal A. Diagnosis and treatment of depression in the elderly medicare population: predictors, disparities, and trends. Journal of the American Geriatrics Society. 2003; 51:1718-1720. [PubMed: 14687349]

Cuijpers P, van Straten A, Smit F. Psychological treatment of late-life depression: a meta-analysis of randomized controlled trials. International Journal of Geriatric Psychiatry. 2006; 21:1139-1149. [PubMed: 16955421]

Fischer LR, Wei F, Solberg LI, Rush WA, Heinrich RL. Treatment of elderly and other adult patients for depression in primary care. Journal of the American Geriatrics Society. 2003; 51:1554-1562. [PubMed: 14687384]

Folstein MF, Folstein SE, McHugh PR. "Mini-mental state". A practical method for grading the cognitive state of patients for the clinician. Journal of Psychiatric Research. 1975; 12:189-198. [PubMed: 1202204]

Fried LP, Ferrucci L, Darer J, Williamson JD, Anderson G. Untangling the concepts of disability, frailty, and comorbidity: implications for improved targeting and care. Journals of Gerontology Series A Biological Sciences \& Medical Sciences. 2004; 59:255-263.

Garrido MM, Kane RL, Kaas M, Kane RA. Use of mental health care by community-dwelling older adults. Journal of the American Geriatrics Society. 2011; 59:50-56. [PubMed: 21198461]

Gill TM, Desai MM, Gahbauer EA, Holford TR, Williams CS. Restricted activity among communityliving older persons: incidence, precipitants, and health care utilization. Annals of Internal Medicine. 2001; 135:313-321. [PubMed: 11529694]

Gill TM, Williams CS, Tinetti ME. Assessing risk for the onset of functional dependence among older adults: the role of physical performance.[erratum appears in J Am Geriatr Soc 1995 Oct;43(10): 1172]. Journal of the American Geriatrics Society. 1995; 43:603-609. [PubMed: 7775716]

Givens JL, Datto CJ, Ruckdeschel K, Knott K, Zubritsky C, Oslin DW, Nyshadham S, Vanguri P, Barg FK. Older patients' aversion to antidepressants. A qualitative study. Journal of General Internal Medicine. 2006; 21:146-151. [PubMed: 16336620]

Hajjar ERC, Hanlon Angela C, Joseph T. Polypharmacy in elderly patients. American Journal of Geriatric Pharmacotherapy. 2007; 5:345-351. [PubMed: 18179993]

Hajjar I, Yang F, Sorond F, Jones RN, Milberg W, Cupples LA, Lipsitz LA. A novel aging phenotype of slow gait, impaired executive function, and depressive symptoms: relationship to blood pressure and other cardiovascular risks. Journals of Gerontology Series A-Biological Sciences \& Medical Sciences. 2009; 64:994-1001.

Harman J, Veazie P, Lyness J. Primary care physician office visits for depression by older Americans. Journal of General Internal Medicine. 2006; 21:926-930. [PubMed: 16918736]

Katon WJ, Lin E, Russo J, Unutzer J. Increased medical costs of a population-based sample of depressed elderly patients. Archives of General Psychiatry. 2003; 60:897-903. [PubMed: 12963671] 
Kennedy GJ, Marcus P. Use of antidepressants in older patients with co-morbid medical conditions: guidance from studies of depression in somatic illness. Drugs \& Aging. 2005; 22:273-287. [PubMed: 15839717]

Klap R, Unroe KT, Unutzer J, Klap R, Unroe KT, Unutzer J. Caring for mental illness in the United States: a focus on older adults. American Journal of Geriatric Psychiatry. 2003; 11:517-524. [PubMed: 14506085]

Koenig HG, George LK. Depression and physical disability outcomes in depressed medically ill hospitalized older adults. American Journal of Geriatric Psychiatry. 1998; 6:230-247. [PubMed: 9659956]

Kohler S, Thomas AJ, Barnett NA, O'Brien JT. The pattern and course of cognitive impairment in late-life depression. Psychological Medicine. 2010; 40:591-602. [PubMed: 19656429]

Kohout FJ, Berkman LF, Evans DA, Cornoni-Huntley J. Two shorter forms of the CES-D (Center for Epidemiological Studies Depression) depression symptoms index. Journal of Aging \& Health. 1993; 5:179-193. [PubMed: 10125443]

Lebowitz BD, Pearson JL, Schneider LS, Reynolds CF 3rd, Alexopoulos GS, Bruce ML, Conwell Y, Katz IR, Meyers BS, Morrison MF, Mossey J, Niederehe G, Parmelee P. Diagnosis and treatment of depression in late life. Consensus statement update. JAMA. 1997; 278:1186-1190. [PubMed: 9326481]

Lyness JM, Cox C, Curry J, Conwell Y, King DA, Caine ED. Older age and the underreporting of depressive symptoms. Journal of the American Geriatrics Society. 1995; 43:216-221. [PubMed: 7884106]

Mamdani MM, Parikh SV, Austin PC, Upshur RE. Use of antidepressants among elderly subjects: trends and contributing factors. American Journal of Psychiatry. 2000; 157:360-367. [PubMed: 10698810]

Mayers AG, Baldwin DS, Mayers AG, Baldwin DS. Antidepressants and their effect on sleep. Human Psychopharmacology. 2005; 20:533-559. [PubMed: 16229049]

Mitchell AJ, Rao S, Vaze A. Do primary care physicians have particular difficulty identifying late-life depression? A meta-analysis stratified by age. Psychotherapy \& Psychosomatics. 2010; 79:285294. [PubMed: 20616623]

Montano CB. Primary care issues related to the treatment of depression in elderly patients. Journal of Clinical Psychiatry. 1999; 20:45-51. [PubMed: 10513859]

Mottram P, Wilson K, Strobl J. Antidepressants for depressed elderly. Cochrane Database of Systematic Reviews. 2006; 1

Nutting PA, Rost K, Smith J, Werner JJ, Elliot C. Competing demands from physical problems: effect on initiating and completing depression care over 6 months. Archives of Family Medicine. 2000; 9:1059-1064. [PubMed: 11115208]

Nyunt MS, Ko SM, Kumar R, Fones CC, Ng TP. Improving treatment access and primary care referrals for depression in a national community-based outreach programme for the elderly. International Journal of Geriatric Psychiatry. 2009; 24:1267-1276. [PubMed: 19319926]

Oxman TE, Hull JG. Social support and treatment response in older depressed primary care patients. Journals of Gerontology Series B Psychological Sciences \& Social Sciences. 2001; 56:35-45.

Panza F, Frisardi V, Capurso C, D’Introno A, Colacicco AM, Imbimbo BP, Santamato A, Vendemiale G, Seripa D, Pilotto A, Capurso A, Solfrizzi V. Late-life depression, mild cognitive impairment, and dementia: possible continuum? American Journal of Geriatric Psychiatry. 2010; 18:98-116. [PubMed: 20104067]

Park M, Unutzer J. Geriatric Depression in Primary Care. Psychiatric Clinics of North America. 2011; 34:469-510. [PubMed: 21536169]

Penninx BW, Leveille S, Ferrucci L, van Eijk JT, Guralnik JM. Exploring the effect of depression on physical disability: longitudinal evidence from the established populations for epidemiologic studies of the elderly. American Journal of Public Health. 1999; 89:1346-1352. [PubMed: 10474551]

Pinquart M, Duberstein PR, Lyness JM. Treatments for later-life depressive conditions: a metaanalytic comparison of pharmacotherapy and psychotherapy. American Journal of Psychiatry. 2006; 163:1493-1501. [PubMed: 16946172] 
Saarto T, Wiffen PJ. Antidepressants for neuropathic pain.[update of Cochrane Database Syst Rev. 2005;(3):CD005454; PMID: 16034979]. Cochrane Database of Systematic Reviews. 2007:CD005454.

Sambamoorthi U, Olfson M, Walkup JT, Crystal S. Diffusion of new generation antidepressant treatment among elderly diagnosed with depression. Medical Care. 2003; 41:180-194. [PubMed: 12544554]

Sirey JA, Bruce ML, Alexopoulos GS, Perlick DA, Raue P, Friedman SJ, Meyers BS. Perceived stigma as a predictor of treatment discontinuation in young and older outpatients with depression. American Journal of Psychiatry. 2001; 158:479-481. [PubMed: 11229992]

Sonnenberg CM, Beekman AT, Deeg DJ, van Tilburg W. Sex differences in late-life depression. Acta Psychiatrica Scandinavica. 2000; 101:286-292. [PubMed: 10782548]

Sonnenberg CM, Beekman AT, Deeg DJ, van Tilburg W. Drug treatment in depressed elderly in the Dutch community. International Journal of Geriatric Psychiatry. 2003; 18:99-104. [PubMed: 12571816]

Sonnenberg CM, Deeg DJ, Comijs HC, van Tilburg W, Beekman AT. Trends in antidepressant use in the older population: results from the LASA-study over a period of 10 years. Journal of Affective Disorders. 2008; 111:299-305. [PubMed: 18442857]

Streim JE, Oslin DW, Katz IR, Smith BD, DiFilippo S, Cooper TB, Ten Have T. Drug treatment of depression in frail elderly nursing home residents. American Journal of Geriatric Psychiatry. 2000; 8:150-159. [PubMed: 10804076]

Szklo M. Population-based cohort studies. Epidemiologic Reviews. 1998; 20:81-90. [PubMed: 9762511]

Tai-Seale M, McGuire T, Colenda C, Rosen D, Cook MA. Two-minute mental health care for elderly patients: inside primary care visits. Journal of the American Geriatrics Society. 2007; 55:19031911. [PubMed: 18081668]

Unutzer J, Katon W, Callahan CM, Williams JW Jr, Hunkeler E, Harpole L, Hoffing M, Della Penna RD, Noel PH, Lin EHB, Tang L, Oishi S. Depression treatment in a sample of 1,801 depressed older adults in primary care. Journal of the American Geriatrics Society. 2003; 51:505-514. [PubMed: 12657070]

Unutzer J, Patrick DL, Marmon T, Simon GE, Katon WJ. Depressive symptoms and mortality in a prospective study of 2,558 older adults. American Journal of Geriatric Psychiatry. 2002; 10:521530. [PubMed: 12213686]

Wang PS, Schneeweiss S, Brookhart MA, Glynn RJ, Mogun H, Patrick AR, Avorn J. Suboptimal antidepressant use in the elderly. Journal of Clinical Psychopharmacology. 2005; 25:118-126. [PubMed: 15738742]

Warshaw G, Bragg E, Freyberg R. Geriatric medicine and geriatric psychiatry clinical services affiliated with U.S. academic medical centers. Journal of the American Geriatrics Society. 2006; 54:690-695. [PubMed: 16686884]

Williams JW Jr, Barrett J, Oxman T, Frank E, Katon W, Sullivan M, Cornell J, Sengupta A. Treatment of dysthymia and minor depression in primary care: A randomized controlled trial in older adults. JAMA. 2000; 284:1519-1526. [PubMed: 11000645]

Wilson KC, Copeland JR, Taylor S, Donoghue J, McCracken CF. Natural history of pharmacotherapy of older depressed community residents. The MRC-ALPHA Study. British Journal of Psychiatry. 1999; 175:439-443. [PubMed: 10789275]

Wright SL, Persad C. Distinguishing between depression and dementia in older persons: neuropsychological and neuropathological correlates. Journal of Geriatric Psychiatry \& Neurology. 2007; 20:189-198. [PubMed: 18004006] 


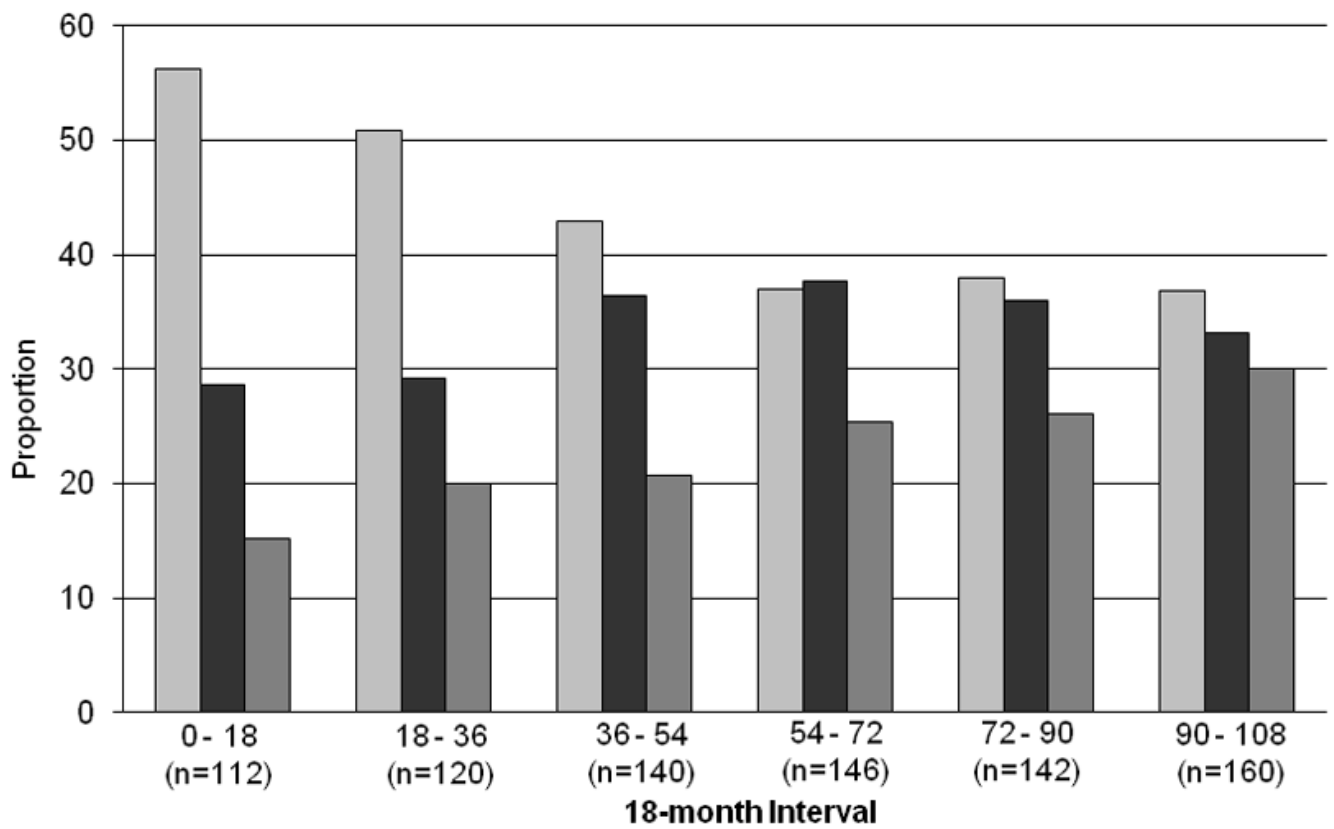

$\square$ Antidepressant Medication $\quad$ MentalHealth Professional $\quad$ Both Treatments

Figure 1.

Profile of depression treatment over 108 months in all study participants. Antidepressant medication use was ascertained during 18-month face-to-face assessments. Use of a mental health professional was collected during monthly telephone assessments. If a participant saw a mental health professional during any of the monthly assessments in a given 18-month interval (e.g., between the 18-month and 36-month assessments), s/he was coded as having seen a mental health professional for depression during that interval. 


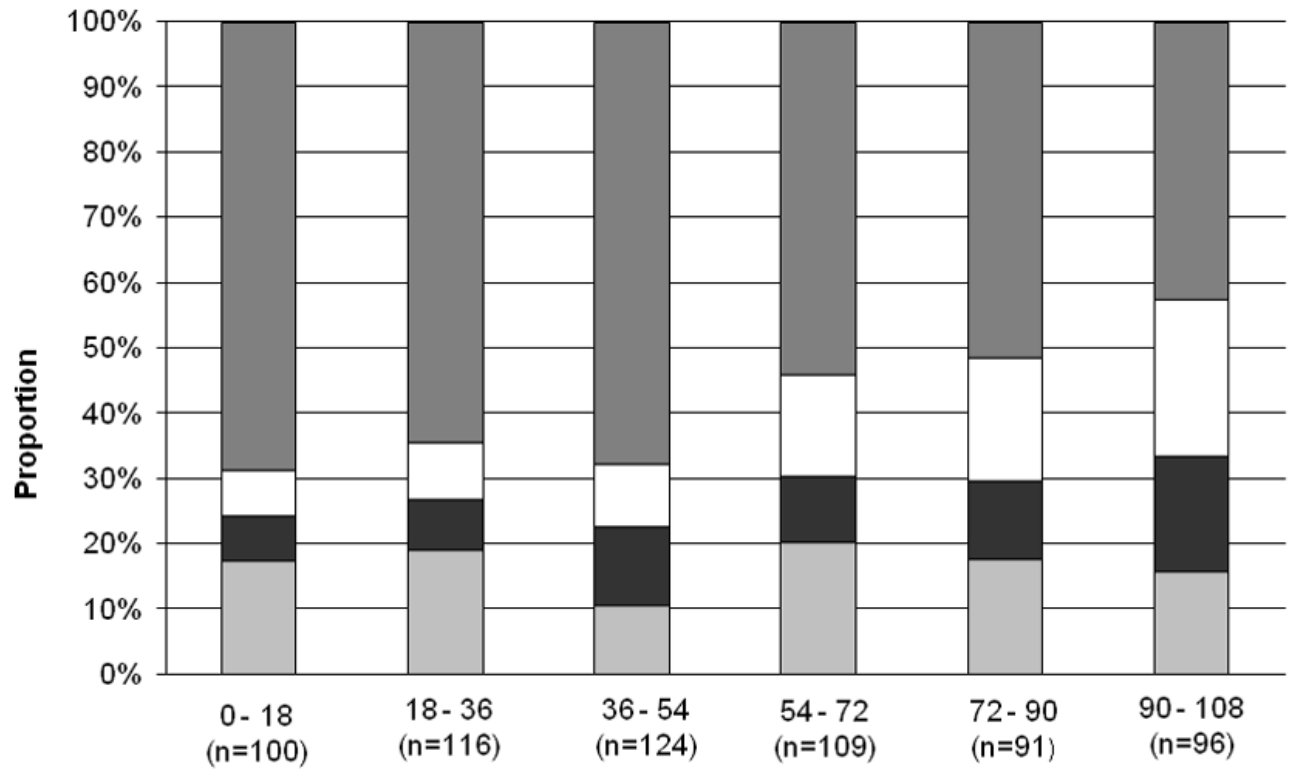

18-month Interval

$\square$ AntidepressantMedication $\square$ MentalHealth Professional $\square$ Both Treatments $\square$ Neither Treatment

Figure 2.

Depression treatment over 108 months in the depressed participants. Antidepressant medication use was ascertained during 18-month face-to-face assessments. Use of a mental health professional was collected during monthly telephone assessments. If a participant saw a mental health professional during any of the monthly assessments in a given 18-month interval (e.g., between the 18-month and 36-month assessments), s/he was coded as having seen a mental health professional for depression during that interval. 


\section{Table 1}

Participant Characteristics.

\begin{tabular}{ll}
\hline Characteristic & N=754 \\
\hline Age in years, mean (SD) & $78.4(5.3)$ \\
Female, n (\%) & $487(64.6)$ \\
White, n (\%) & $682(90.5)$ \\
Years of education, mean (SD) & $12.0(2.0)$ \\
Number of chronic conditions, mean (SD) ${ }^{*}$ & $1.7(1.2)$ \\
Cognitive status, mean (SD) ${ }^{\dagger}$ & $26.8(2.5)$ \\
Physical frailty, n (\%) & $195(25.7)$ \\
Depressed, n $(\%)^{\S}$ & $100(13.3)$ \\
\hline
\end{tabular}

$\mathrm{SD}=$ Standard Deviation

* Includes 9 self-reported, physician-diagnosed chronic conditions: hypertension, myocardial infarction, congestive heart failure, stroke, diabetes mellitus, arthritis, hip fracture, chronic lung disease, and cancer (other than minor skin cancer).

${ }^{\dagger}$ Assessed by the Mini Mental State Examination (MMSE).

* Completed a 10 -foot rapid gait walk in $>10$ seconds.

$\S_{\text {Score }} \geq 20$ on the Center for Epidemiological Studies - Depression (CES-D) scale. 


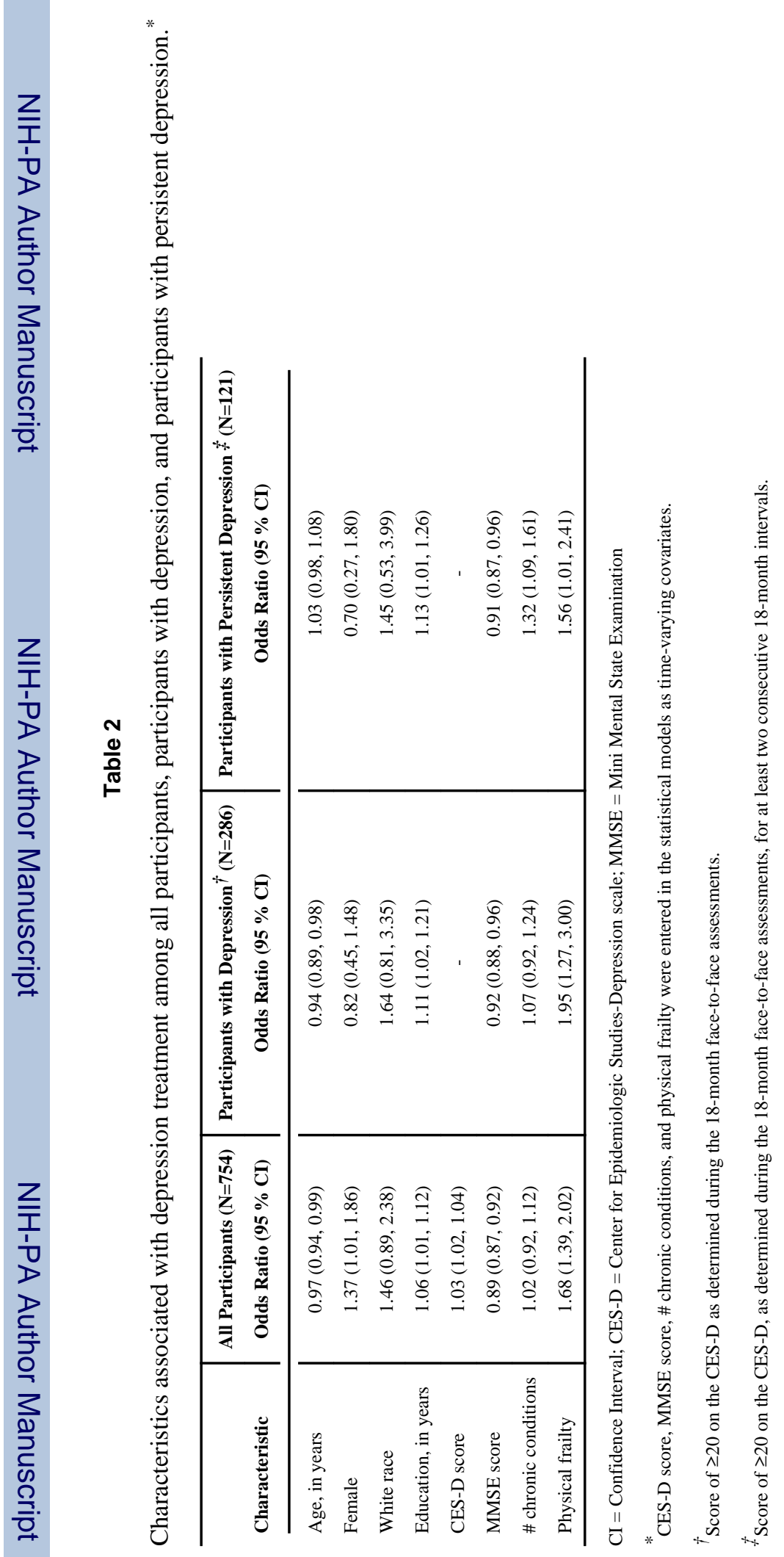

J Affect Disord. Author manuscript; available in PMC 2013 February 1. 